\title{
Comparison of algorithms to retrieve Land Surface Temperature from LANDSAT-7 ETM+ IR data in the Basilicata Ionian band
}

\author{
V. A. Copertino, M. Di Pierro, G. Scavone and V. Telesca \\ Department of Engineering and Environmental Physics, University of Basilicata, Viale dell'Ateneo Lucano, 10, 85100, \\ Potenza, Italy \\ Received: 28-III-2011 - Accepted: 27-IV-2012 - Original version
}

Correspondence to: scavone@unibas.it

\begin{abstract}
Land Surface Temperature (LST) is an extremely important parameter that controls the exchange of longwave radiation and sensible heat flux between the Earth's surface and the atmosphere. Therefore knowledge of LST is essential for a range of issues and themes in Earth sciences central to hydrology, climatology and global environmental change. In particular, it plays a main role in estimating hydrological variables, such as evapotranspiration. However, because of the extreme heterogeneity of most natural land surfaces, LST is a difficult parameter to estimate and to validate. In this study, two models by Qin et al. and Jiménez-Muñoz and Sobrino were applied and compared for the evaluation of the LST on the Basilicata region (Southern Italy). These models were proposed in literature as alternatives to the application of the Radiative Transfer Equation (RTE) in order to overcome some difficulties in obtaining data from radio sounding and in schematizing mass and energy exchange processes in the atmosphere. Two images from Landsat-7 ETM+ (9th August, 1999; 14th June, 2002), covering the whole Basilicata region, were processed to obtain maps of LST. The required meteorological variables, air temperature and relative humidity, global solar radiation and wind speed, were obtained by interpolating data from a network of agro-meteorological stations distributed within the region. The variability of the LSTs retrieved was investigated with respect to different land use types characterized from the CORINE Land Cover map. Then a comparison was made between the LST retrieved by the application of the Qin et al. and the Jiménez-Muñoz and Sobrino models and the in situ measurements of surface temperature taken at ALSIA (Agenzia Lucana di Sviluppo e di Innovazione in Agricoltura) weather stations located in the Ionian band of the Basilicata region. The results show (in agreement with previous works) that the Jiménez-Muñoz and Sobrino model, in this case, is better able to approximate the measured data than the Qin et al. model, also using Landsat-7 ETM+ images and in a different context, such as that of the Lucan Ionian band.
\end{abstract}

Key words: Land Surface Temperature, Landsat, emissivity, land use

\section{Introduction}

As is well known, Land Surface Temperature (LST) is one of the key parameters in the physics of land-surface processes on regional and global scales, combining surfaceatmospheric interactions and the energy fluxes between the atmosphere and the ground (Wan and Snyder, 1996). LST is required for a wide variety of scientific studies - from climatology to hydrology to ecology and biogeology (Running et al., 1994), providing important information about the surface physical properties and climate which plays a key role in many environmental processes (Dousset and Gourmelon, 2003; Weng et al., 2004; Mallick et al., 2008).

The LST over an entire large area could easily be acquired by using satellite thermal remote sensing technology (Zhang et al., 2006). However, an accurate estimate of the LST from IR remote sensing data requires knowledge of many influencing parameters, because it is controlled by the 
atmospheric state and surface emissivity. Given the great importance in modeling and applying the LST, despite the difficulties in taking into account all the influential parameters, several models have been developed in literature, characterized by a different set of applications, that combine thermal satellite and field data to obtain an accurate estimation of this variable.

As far as the Landsat TM and ETM+ are concerned, three different single-channel methods have been proposed to retrieve the LST from their thermal bands (Sobrino et al., 2004). These three methods are: (i) Radiative Transfer Equation, (ii) the Qin et al. (2001) mono-window algorithm, and (iii) the Jiménez-Muñoz and Sobrino (2003) single-channel algorithm. The first method requires accurate knowledge of atmospheric parameters, such as transmissivity and atmospheric upwelling and downwelling radiances, which is not always possible. In particular, in situ atmospheric profiles from radiosondes launched simultaneously with the satellite passes are needed and this is a big constraint on using it (Zhang et al., 2006). The second and third methods, usually used when ground truth data are not available, represent two alternatives to the Radiative Transfer Equation for the LST retrieving, in order to simplify the atmospheric correction processes.

Numerous factors need to be quantified in order to assess the accuracy of the LST retrieval from satellite thermal data, including sensor radiometric calibrations (Wukelic et al., 1989), atmospheric correction (Cooper and Asrar, 1989), surface emissivity correction (Norman et al., 1990), and characterization of spatial variability in land cover.

In particular, surface temperature measurements are strongly affected by atmospheric effects, particularly by water vapor absorption, therefore a correction method is absolutely necessary. Moreover, the LST estimation by means of passive thermal remote sensing depends on accurate emissivity specification (Becker and Li, 1990). Land Surface Emissivity (LSE) measurement by remote sensing has the disadvantage that the temperature and emissivity cannot be calculated simultaneously because the number of unknown variables is always higher than the number of measurements. To overcome this, qualitative approximations have to be made, for example assuming a constant value of the emissivity for all bands or introducing a hypothesis such as relating emissivity to some vegetation variables. For example, the Vegetation Cover Method (VCM) developed by Valor and Caselles (1996) is based on the relationship between emissivity in the thermal infrared and the Normalized Difference Vegetation Index (NDVI).

In the past, the impossibility of applying a split-window equation and the difficulty of having temporarily coincident radio soundings meant that Landsat data was not often used to obtain the surface temperature. However, recently, the use of these data for the LST retrieval has increased due to the development of models based on the only thermal channel (TM6) of Landsat sensors, such as the mono-window algorithm of Qin et al. (2001) and the single-channel algorithm of Jiménez-Muñoz and Sobrino (2003). In this study, these two models were applied to Landsat-7 ETM+ images, corresponding to 9th August, 1999 and 14th June, 2002, and covering the whole Basilicata region, to evaluate the LST at a regional scale. The main objectives of this study were: (i) to assess the performance of the two models and to compare them to each other, checking them in a different geographical and climatologic area from those for which they were initially developed and applied; (ii) to improve the reliability of some models, such as the evapotranspiration retrieval ones, that involve the LST as one of the main parameters; (iii) to have an LST modeling of more immediate application compared to the RTE, depending on the available images, so as to overcome the difficulties in obtaining data from radiosounding and in approximating the schematization of the energy exchange processes in the atmosphere; (iv) to link and compare information deriving from satellite and field data.

The emissivity estimation was made using an NDVI method, while the variability with different land uses of the LST retrieved was compared to the surface temperature measurements from the meteorological stations located in the Ionian band of the Basilicata region, referring to CORINE Land Cover map (APAT, 2005).

\section{Models for Land Surface Temperature retrieval}

In this Section, two models for LST retrieval from remote sensing are described: (i) the Qin et al. mono-window algorithm 2001 and (ii) the Jiménez-Muñoz and Sobrino single-channel algorithm 2003.

\subsection{The Qin et al. mono-window algorithm 2001}

Qin et al. (2001) developed a mono-window algorithm to obtain the LST from the TM6 thermal band of the Thematic Mapper sensor on board the Landsat-5 satellite. This algorithm was expressed as follows:

$$
\begin{aligned}
T_{s} & =\frac{a_{6}}{C_{6}}\left(1-C_{6}-D_{6}\right)+ \\
& +\frac{b_{6}}{C_{6}}\left[\left(1-C_{6}-D_{6}\right)+C_{6}+D_{6}\right] T_{\text {sensor }}-\frac{D_{6}}{C_{6}} T_{a}
\end{aligned}
$$

where $T_{s}$ is the land surface temperature in $\mathrm{K} ; T_{\text {sensor }}$ is the at-sensor brightness temperature in $\mathrm{K}$ computed from Landsat TM band 6; $a_{6}=-67.355351, b_{6}=0.458606 ; C_{6}=\varepsilon \tau_{6}$; $D_{6}=\left(1-\tau_{6}\right)\left[1+(1-\varepsilon) \tau_{6}\right]$, where $\varepsilon$ is the land surface emissivity and $\tau_{6}$ the total atmospheric transmittance; $T_{a}$ is the effective mean atmospheric temperature in $\mathrm{K}$ given for midlatitude (Zhang et al., 2006) by:

$T_{a}=16.0110+0.92621 T_{o}$

$T_{o}$ being the near surface air temperature. $T_{a}, \varepsilon$ and $\tau_{6}$ are the three parameters needed to convert the brightness temperature to LST. 
The model proposed by Qin et al. (2001) also estimates the atmospheric transmittance from atmospheric water vapor content, $w$, for the range $0.4-1.6 \mathrm{~g} \mathrm{~cm}^{-2}$ :

$\tau=0.974290-0.08007 w\left(h i g h T_{o}\right)$

$\tau=0.982007-0.09611 w\left(\operatorname{low} T_{o}\right)$

where the relation between the water vapor content and the atmospheric transmittance is considered under two near surface atmospheric temperatures: low profile, defined as $18^{\circ} \mathrm{C}$ (Equation 3), and high profile, defined as $35^{\circ} \mathrm{C}$ (Equation 4).

\subsection{The Jiménez-Muñoz and Sobrino single-channel algorithm 2003}

Jiménez-Muñoz and Sobrino (2003) developed a generalized single-channel method to retrieve LST from only one thermal channel, where LST is given by the following equation:

$T_{s}=\gamma\left[\varepsilon^{-1}\left(\psi_{1} L_{\text {sensor }}+\psi_{2}\right)+\psi_{3}\right]+\delta$

with:

$\gamma=\left\{\frac{c_{2} L_{\text {sensor }}}{T_{\text {sensor }}^{2}}\left[\frac{\lambda^{4}}{c_{1}} L_{\text {sensor }}+\lambda^{-1}\right]\right\}^{-1}$

$\delta=-\gamma L_{\text {sensor }}+T_{\text {sensor }}$

where $T_{s}$ is the land surface temperature in $\mathrm{K} ; L_{\text {sensor }}$ is the at-sensor radiance in $\mathrm{W} \mathrm{m}{ }^{-2} \mathrm{sr}^{-1} \mu \mathrm{m}^{-1}, T_{\text {sensor }}$ is the at-sensor brightness temperature in $\mathrm{K}, \lambda$ is the effective wavelength in $\mu \mathrm{m}$ (11.457 $\mu \mathrm{m}$ for the TM6 band), $c_{1}=1.19104 \cdot 10^{8} \mathrm{~W} \mu \mathrm{m}^{-2} \mathrm{sr}^{-1}$ and $c_{2}=14387.7 \mu \mathrm{m} \mathrm{K}$. The atmospheric functions $\psi_{1}, \psi_{2}$ and $\psi_{3}$ can be obtained as functions of the total atmospheric water vapor content $(w)$ according to the following equations particularized for TM/ETM+ data in band 6 (Sobrino et al., 2004):

$\psi_{1}=0.14714 w^{2}-0.15583 w+1.1234$

$\psi_{2}=-1.1836 w^{2}-0.37607 w-0.52894$

$\psi_{3}=-0.04554 w^{2}+1.8719 w-0.39071$

\section{Land surface emissivity estimation using the NDVI method}

The retrieval of LST from satellite data requires the correction of the effects introduced by the atmosphere, mainly the absorption and emission of atmospheric water vapor and the surface emissivity, which can be significantly lower than unity and varies spatially with surface cover and type (Coll et al., 2005). Land Surface Emissivity (LSE) is required for applying both the above described methods for estimating the LST from Landsat images. The single thermal channel
(TM6) of the Landsat satellites makes it impossible to apply methods that are well known and accepted by the scientific community working in the thermal infrared, such as TES (Temperature and Emissivity Separation) algorithm (Gillespie et al., 1998).

An alternative, operative, easy to apply procedure is to obtain the LSE image from the NDVI (Normalized Difference Vegetation Index). Among the different approaches available in literature (Sobrino and Raissouni, 2000; Valor and Caselles, 1996; Van de Griend and Owe, 1993) in this study the NDVI Thresholds Method-NDVI ${ }^{T H M}$ was used.

This method was originally developed and applied to AVHRR data over a study area located in Morocco by Sobrino and Raissouni (2000). The application of the $\mathrm{NDVI}^{T H M}$ to TM data acquired over the Requena-Utiel site (Valencia, Spain) was analyzed in Sobrino et al. (2004), while the application to TM data acquired over the Barrax area was analyzed in Sobrino et al. (2008).

The NDVI ${ }^{T H M}$ method obtains the emissivity values from the NDVI considering different cases (Sobrino et al., 2004):

- NDVI $<0.2$

In this case, the pixels are considered as bare soil and the emissivity is obtained from reflectivity values in the red region.

\section{- $\mathrm{NDVI}>0.5$}

Pixels with NDVI values higher than 0.5 are considered to be fully vegetated, and then a constant value for the emissivity is assumed, typically of 0.99 .

\section{- $0.2 \leq \mathrm{NDVI} \leq 0.5$}

In this case, the pixels are composed by a mixture of bare soil and vegetation, and the emissivity is calculated according to the following equation:

$\varepsilon=\varepsilon_{v} P_{v}+\varepsilon_{s}\left(1-P_{v}\right)+d \varepsilon$

where $\varepsilon_{v}$ and $\varepsilon_{s}$ are vegetation and soil emissivity respectively, $P_{v}$ is the vegetation proportion obtained according to Carlson and Ripley (1997):

$P_{v}=\left[\frac{N D V I-N D V I_{\min }}{N D V I_{\max }-N D V I_{\min }}\right]^{2}$

where $N D V I_{\max }=0.5$ and $N D V I_{\min }=0.2$.

In the present study, values of $N D V I_{\max }$ and $N D V I_{\min }$ were calculated for each image in place of these standard values.

The term $d \varepsilon$ in the Equation 11 includes the effect of the geometrical distribution of the natural surfaces and also the internal reflections. For plain surfaces this term is negligible, but for heterogeneous and rough surfaces, such as forests, it can reach a value of $2 \%$ (Sobrino, 1989). A good approximation for this term can be obtained from the equation:

$d \varepsilon=\left(1-\varepsilon_{s}\right)\left(1-P_{v}\right) F \varepsilon_{v}$ 


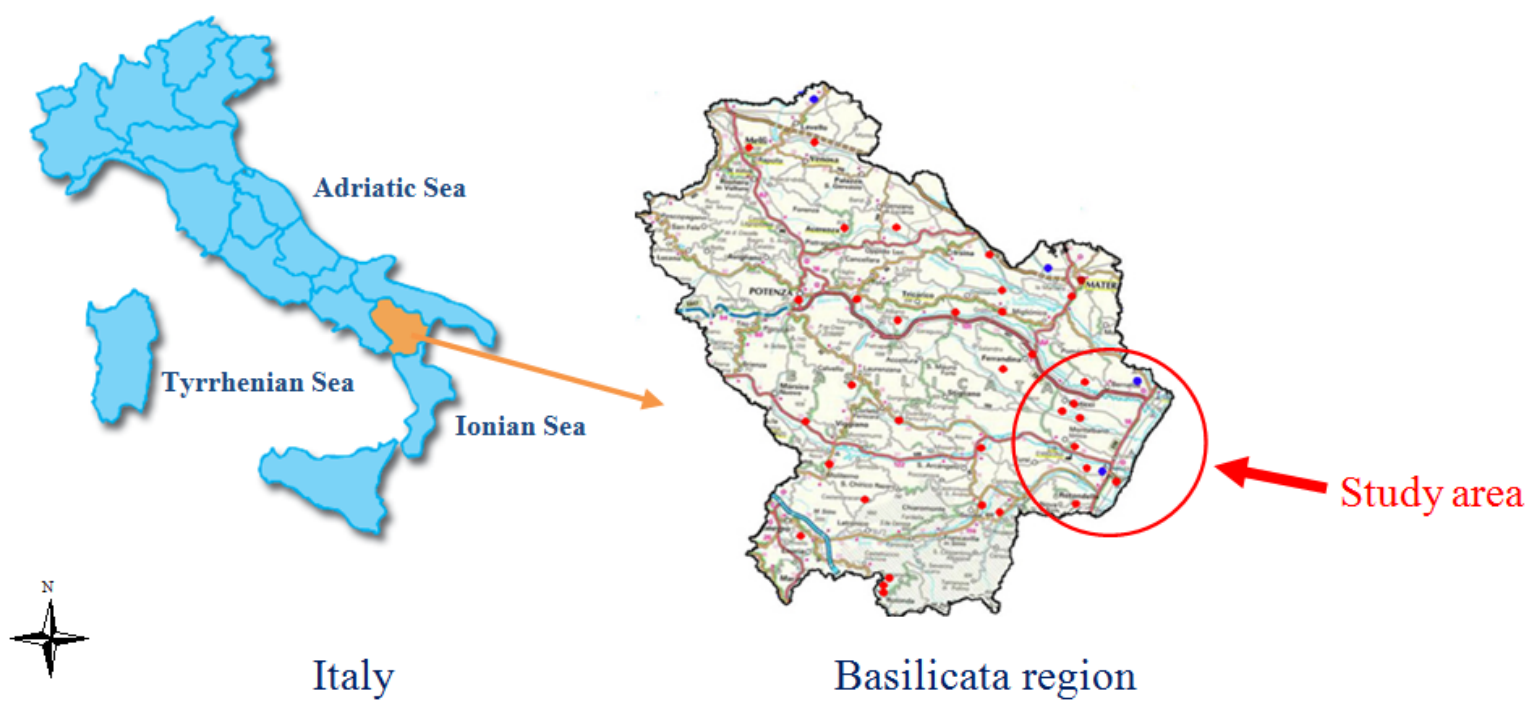

Figure 1. Study area: Basilicata Ionian band (Southern Italy).

where $F$ is a shape factor (Sobrino et al., 1990) whose mean value, assuming different geometrical distributions, is 0.55 .

Taking into account Equations 7 and 9, the LSE can be obtained as:

$\varepsilon=m P_{v}+n$

where:

$m=\varepsilon_{v}-\varepsilon_{s}-\left(1-\varepsilon_{s}\right) F \varepsilon_{v}$

$n=\varepsilon_{s}+\left(1-\varepsilon_{s}\right) F \varepsilon_{v}$

In order to apply this methodology, values of soil and vegetation emissivity are needed. For this purpose, a typical emissivity value of 0.99 for full vegetation was chosen. Choosing a typical value for the soil is more difficult due to the higher variability in the soils emissivity values in comparison to vegetation. A possible solution is to use the mean values for the soils emissivity included in the ASTER spectral library (http://asterweb.jpl.nasa.gov) and filtered according to band TM6 filter function. In this way, considering a total of 49 soils spectra, a mean value of 0.973 (with a standard deviation of 0.004) was obtained. Using these data (TM6 soil and vegetation emissivity of 0.97 and 0.99 , respectively), the final expression for the LSE is given by (Sobrino et al., 2004):

$\varepsilon_{T M 6}=0.004 P_{v}+0.986$

\section{NDVI calculation}

The NDVI data required for retrieving the LSE can be provided by TM3 and TM4 bands, in the red and near infrared respectively, by applying the following equation:

$N D V I=\frac{T M 4-T M 3}{T M 4+T M 3}$
In this work, an atmospheric correction method based on image data was applied for TM3 and TM4 bands.

\subsection{Atmospheric correction based on image data}

This method was developed by Chavez (1996), and its main advantage is that the data needed to perform the atmospheric correction can be obtained from the image itself. The at-surface reflectivity is calculated using the following equation:

$\rho_{\mathrm{sup}}=\frac{\pi\left(L_{s a t}-L_{p}\right) d^{2}}{E_{o} \cos \theta_{z} T_{z}}$

where $L_{s a t}$ is the at-sensor radiance, $T_{z}$ is the atmospheric transmittance between the sun and the surface, $\theta_{z}$ is the zenithal solar angle, $E_{o}$ is the spectral solar irradiance at the top of the atmosphere, $d$ is the Earth-Sun distance, and $L_{p}$ is the radiance resulting from the interaction of electromagnetic radiance with the atmospheric components (molecules and aerosols) that can be obtained by:

$L_{p}=L_{\min }-L_{1 \%}$

where $L_{\min }$ is the radiance corresponding to a digital count value for which the sum of all the pixels with digital counts lower or equal to this value is equal to $0.01 \%$ of all the pixels in the considered image. The term $L_{1 \%}$ is given by:

$L_{1 \%}=\frac{0.01 \cos \theta_{z} T_{z} E_{o}}{\pi d^{2}}$

with values for $T_{z}$ of 0.85 and 0.91 for TM3 and TM4 bands, respectively (Chavez, 1996). 


\section{Study area}

In this study, the Ionian band of the Basilicata region (Figure 1), which is a typical Mediterranean area, was chosen as the study area due to both the social-economic and touristic importance that it has for the Basilicata region, as well as for the availability of useful data for the application of climatic and hydrological models.

In particular, field meteorological data are provided by ALSIA (Agenzia Lucana di Sviluppo e di Innovazione in Agricoltura) stations.

ALSIA stations are equipped with instruments for continuous and automatic measurements of meteorological parameters. The service, activated in 1996, operates a network of 38 agro-meteorological stations distributed throughout the region, surveying the following parameters:

- air temperature $\left({ }^{\circ} \mathrm{C}\right)$

- soil temperature $\left({ }^{\circ} \mathrm{C}\right)$

- relative humidity $(\%)$

- precipitation (mm)

- wind speed $\left(\mathrm{km} \mathrm{h}^{-1}\right)$ and direction

- global solar radiation $\left(\mathrm{M} \mathrm{J} \mathrm{m}^{-2}\right)$

- leaf wetness (min)

The service is organized on two levels:

- Level I. Activities related to the maintenance of the station network.

- Level II. Activities related to the quality control of data and their reconstruction, the editing of the weekly agrometeorological bulletin, regional and climatologic analysis and studies.

The only real plain in the region stretches along the coastal plain on the Ionian Sea. The short coastline $(\sim 15 \mathrm{~km})$ along the Tyrrhenian Sea is high and rocky, while the approximately $35 \mathrm{~km}$ of shore, on the Ionian coast, from Metaponto to Nova Siri, are characterized by predominantly sandy beaches, where 5 of the main Basilicata rivers flow to the sea: Bradano, Basento, Cavone, Agri and Sinni, representing the primary drainage network of the Basilicata region. The cultivated areas of the Metaponto plain, which extends behind the coastal band, rich in historical and natural resources, bordering the Ionian Sea to the South-East and behind a declining hill, represent a real treasure for the regional agriculture whose production of fruit and vegetables is exported to all over the Europe.

The Ionian band is characterized by a warm temperate Mediterranean climate. The average annual temperature varies from $14.5^{\circ} \mathrm{C}$ to $16.9^{\circ} \mathrm{C}$, while the monthly average temperature is colder, varying between $6^{\circ} \mathrm{C}$ and $9.9^{\circ} \mathrm{C}$. Rainfall is very irregular but, overall, not scarce; generally it increases proceeding from South to North and from East to West, where the high massifs exert a more notable wind capture action.

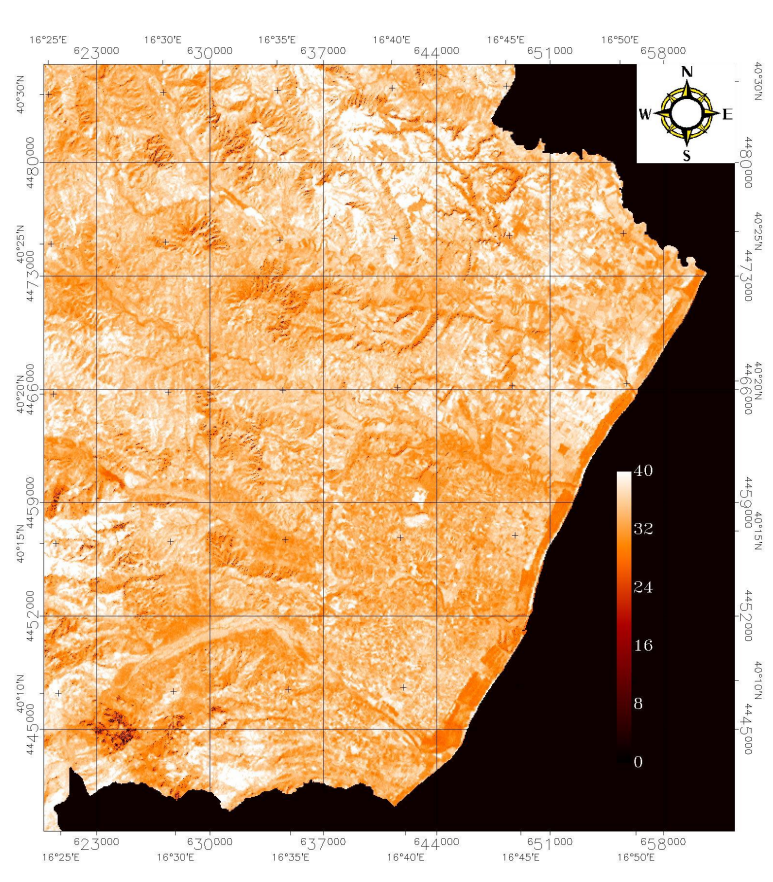

Figure 2. Map of Land Surface Temperature from the application of the Qin et al. (2001) algorithm to 9th August, 1999 Landsat-7 ETM+ image.

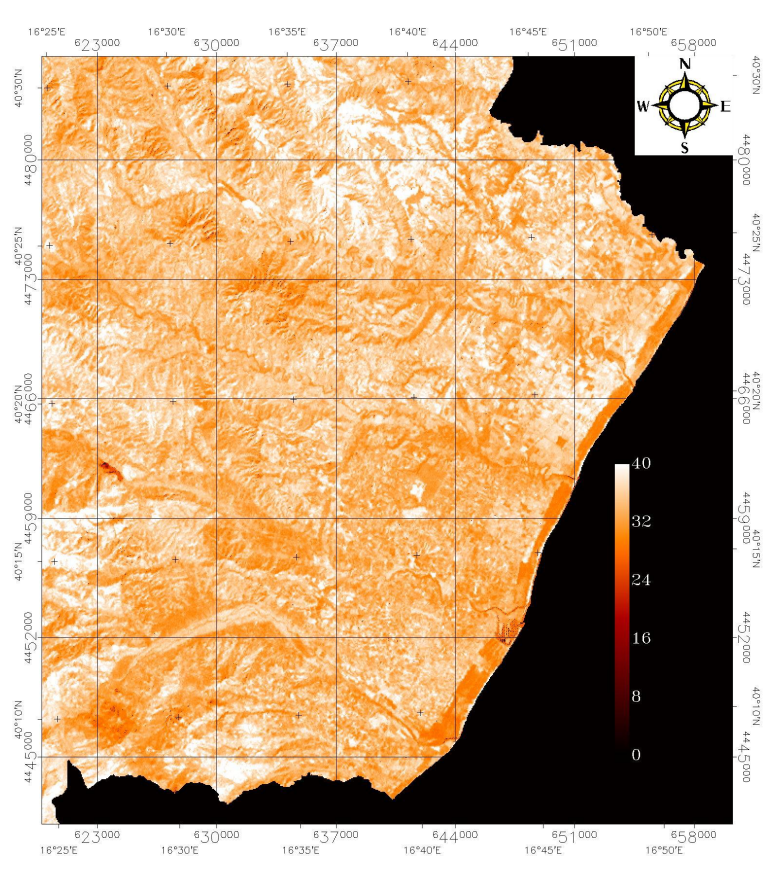

Figure 3. Map of Land Surface Temperature from the application of the Qin et al. (2001) algorithm to 14th June, 2002 Landsat-7 ETM+ image. 


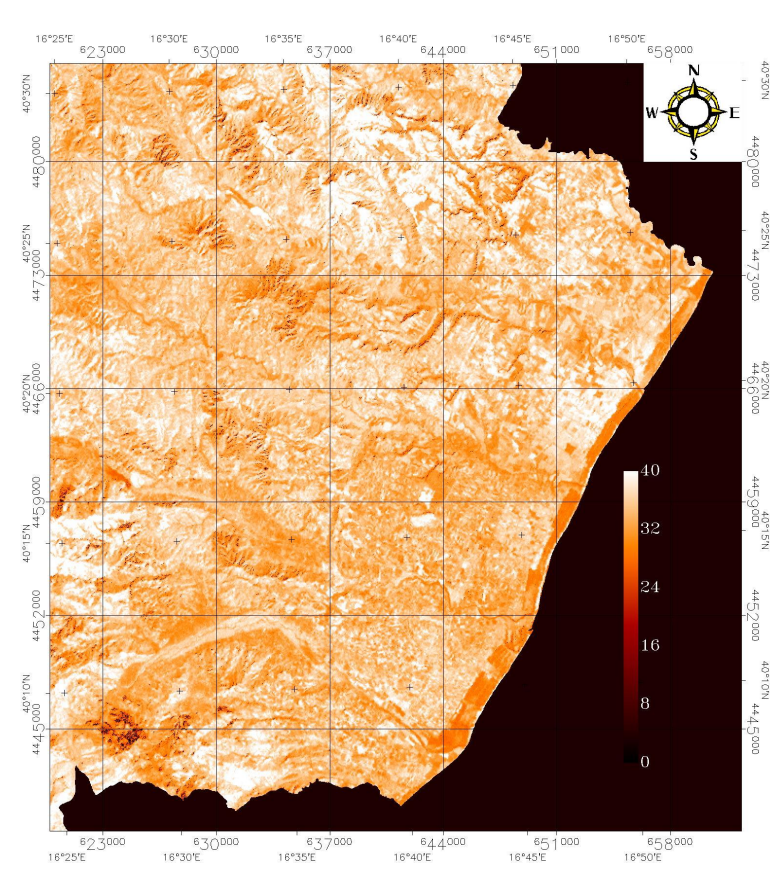

Figure 4. Map of Land Surface Temperature from the application of the Jiménez-Muñoz and Sobrino (2003) algorithm to 9th August, 1999 Landsat-7 ETM+ image.

\section{Application of mono-window and single- channel models to the Basilicata region}

The generalized single channel algorithm, originally developed and particularized to the Thermal-Infrared (TIR) channel (band 6) located on the Landsat-5 Thematic Mapper (TM) sensor, was subsequently updated and extended to the TIR channel of the TM sensor onboard the Landsat4 platform and the Enhanced TM plus sensor onboard the Landsat-7 platform by Jiménez-Muñoz et al. (2009). The air temperature was also added to the algorithm in Cristóbal et al. (2009). Also, the Qin et al. (2001) algorithm was originally developed for the Landsat-5 TM and then applied to Landsat-7 ETM+ by other authors (Jiménez-Muñoz and Sobrino, 2003; Zhang et al., 2006; Zhang et al., 2007; Sun et al., 2010; etc.).

In the present study, both the Qin et al. (2001) and the Jiménez-Muñoz and Sobrino (2003) algorithms were applied to the Basilicata region and compared to each other. For this purpose, two satellite images coming from the Enhanced Thematic Mapper Plus (ETM+) on board the Landsat-7, corresponding to 9th August, 1999 and 14th June, 2002, were processed. The Ionian area of the region was extrapolated from the two satellite images of the Basilicata (Figure 1).

The land surface emissivity required for the implementation of the two LST retrieval models was estimated by an NDVI method, based on the visible and near infrared bands, TM3 and TM4, as described in Section 3. In order to apply Equation 12 and calculate the vegetation cover, $P_{v}$, needed

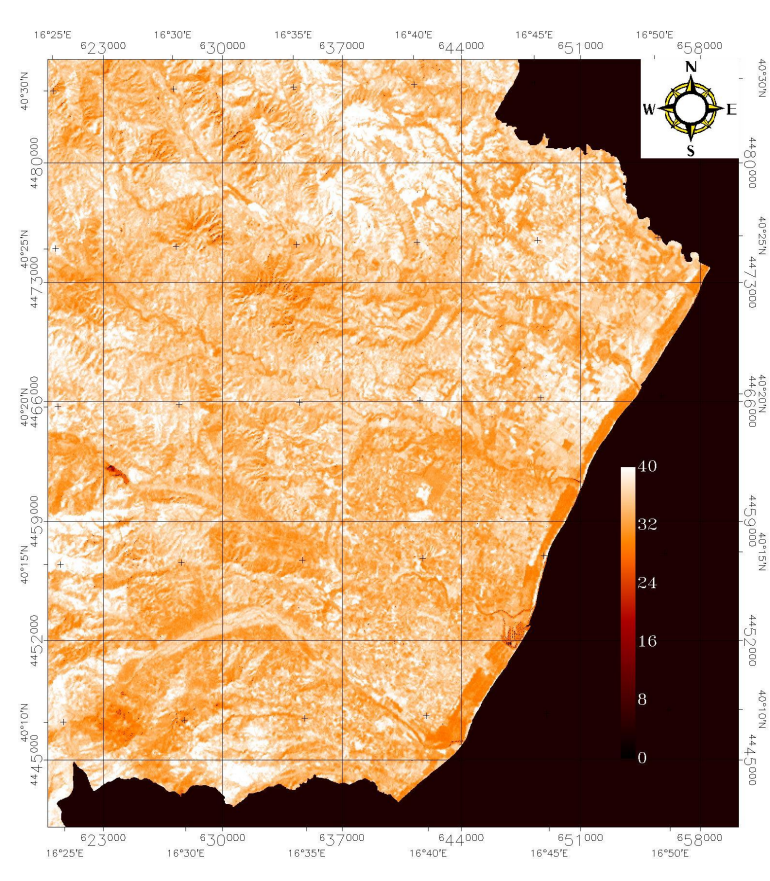

Figure 5. Map of Land Surface Temperature from the application of the Jiménez-Muñoz and Sobrino (2003) algorithm to 14th June, 2002 Landsat-7 ETM+ image.

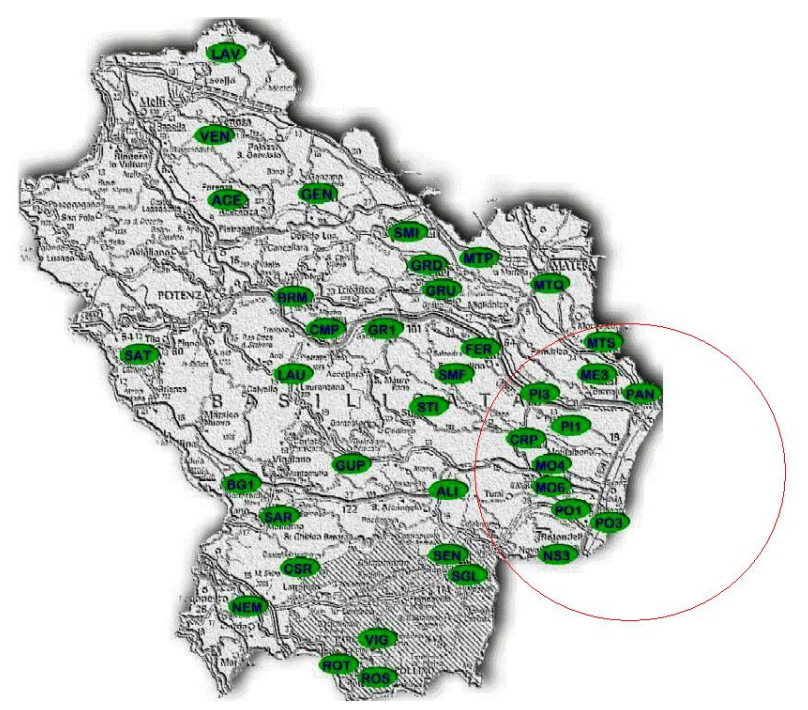

Figure 6. Location of the meteorological ALSIA stations in the Ionian band of the Basilicata region (Southern Italy).

in Equation 17 for the emissivity estimation, $N D V I_{\min }$ and $N D V I_{\max }$, corresponding to bare soil and full vegetation respectively, were determined from the total NDVI map.

The atmospheric correction of TM3, TM4 and TM6 bands was made usint the Chavez (1996) method, based on image data, by implementing Equations 15, 16 and 17.

The image processing was automated through the development of the two algorithms in Matlab environment. 


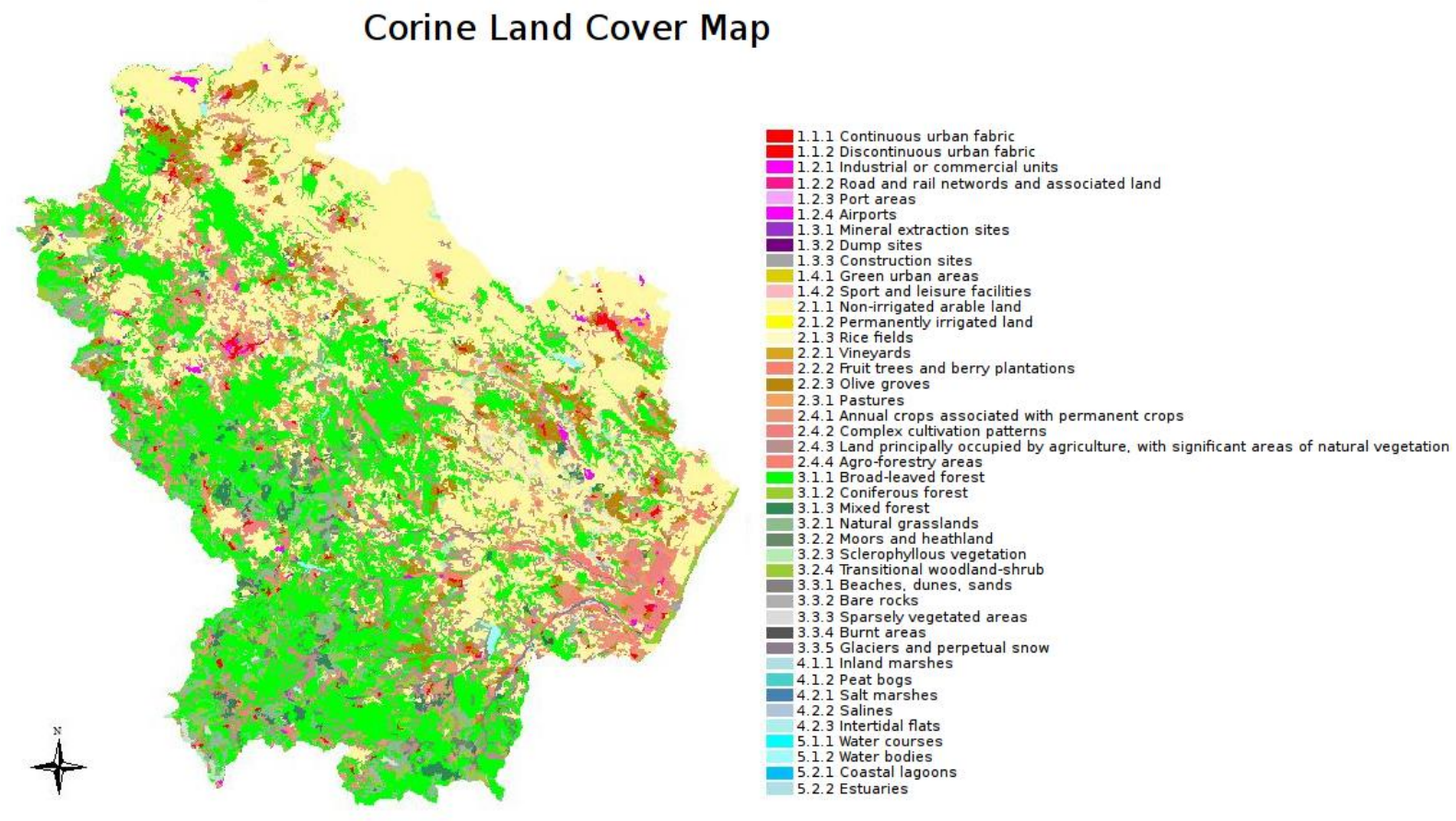

Figure 7. CORINE Land Cover 2000.

\subsection{The Qin et al. (2001) mono-window algorithm}

The Qin et al. mono-window algorithm 2001 was applied to the Landsat-7 images of 9th August, 1999 and 14th June, 2002.

The C.U.T. time (Coordinated Universal Time) of the Landsat-7 passage is 9:30, corresponding to 11:30 Local Time. It is the same for both images, while sun elevations are different: $45.2^{\circ}$ for the 1999 image and $25.74^{\circ}$ for the 2002 one.

The input parameters for the Matlab program implementation were: TM3, TM4 and TM6 bands maps; characteristics of the bands; atmospheric parameters, such as water vapor content, air temperature measurements from ALSIA stations; a series of parameters including $d, N D V I_{m i n}$, $N D V I_{\max }, \theta, L_{p}$.

The atmospheric water vapor content, $w$, required by the Equations $6 \mathrm{a}-6 \mathrm{c}$, was calculated by applying the empirical method of the Leckner equation presented in Iqbal (1983) which is expressed as:

$w=\frac{0.493 \phi_{r} P_{s}}{T_{o}}$

where $\phi_{r}$ is the relative humidity in fraction; $T_{o}$ is the near surface air temperature in $\mathrm{K}$ and $P_{s}$ is the partial pressure of water vapor given as:

$P_{s}=\exp \left(26.23-\frac{5416}{T_{o}}\right)$
Then the land surface temperature maps were obtained by applying the Equations 1, 2, 3a and $3 b$.

The Matlab code subsequently ran the following calculations:

- $N D V I$

- vegetation cover, $P_{v}$; emissivity, $\varepsilon$; brightness temperature, $T_{\text {sensor }}$

- mean atmospheric temperature, $T_{a} ; C_{6}$ and $D_{6}$

- Land Surface Temperature, $T_{s}$

Land Surface Temperature maps coming from the application of the Qin et al. (2001) algorithm to 9th August, 1999 and 14th June, 2002 Landsat-7 ETM+ images are shown in Figure 2 and Figure 3 respectively.

\subsection{The Jiménez-Muñoz and Sobrino (2003) single- channel algorithm}

A code similar to the previously described one was developed for applying the Jiménez-Muñoz and Sobrino (2003) single-channel algorithm. It ran the following calculations in succession:

- NDVI

- vegetation cover, $P_{v}$; emissivity, $\varepsilon$; brightness temperature, $T_{\text {sensor }}$

- $\delta$ and $\gamma$; atmospheric functions, $\psi_{1}, \psi_{2}, \psi_{3}$

- Land Surface Temperature, $T_{s}$ 
Table 1. Comparison of results for Landsat-7, 9th August, 1999 image.

\begin{tabular}{|c|c|c|c|c|c|c|c|c|c|}
\hline Land cover/use & $\begin{array}{l}T s_{m_{-} J} \\
{ }^{\circ} \mathrm{C}\end{array}$ & $\sigma_{J}$ & $\begin{array}{c}T s_{m-} Q \\
{ }^{\circ} \mathrm{C}\end{array}$ & $\sigma_{Q}$ & $\begin{array}{c}T s_{m_{-}} A \\
{ }^{\circ} \mathrm{C}\end{array}$ & $\sigma_{A}$ & & $\Delta_{J}$ & $\Delta_{Q}$ \\
\hline 2.1 Arable land & 27.69 & 2.4 & 25.31 & 2.32 & 26.75 & 0.67 & & -0.94 & 1.44 \\
\hline 2.2 Permanent crops & 26.28 & 2.38 & 23.94 & 2.34 & 26.53 & 0.88 & & 0.25 & 2.59 \\
\hline $\begin{array}{l}2.4 \text { Heterogeneous } \\
\text { agricultural areas }\end{array}$ & 26.45 & 2.46 & 24.10 & 2.18 & 26.34 & 0.76 & & -0.11 & 2.24 \\
\hline $\begin{array}{l}3.2 \mathrm{Scrub} \text { and/or } \\
\text { herbaceous vegetation } \\
\text { associations }\end{array}$ & 27.28 & 2.62 & 24.92 & 2.61 & 26.62 & 0.59 & & -0.66 & 1.70 \\
\hline \multirow[t]{4}{*}{$\begin{array}{l}3.3 \text { Open spaces with } \\
\text { little or no vegetation }\end{array}$} & 27.04 & 5.09 & 24.69 & 4.86 & 26.51 & 0.63 & & -0.53 & 1.82 \\
\hline & & & & & & & $\Delta_{m}$ & -0.40 & 1.96 \\
\hline & & & & & & & $\sigma$ & 0.47 & 0.46 \\
\hline & & & & & & & $R M S D$ & 0.58 & 2.00 \\
\hline
\end{tabular}

Table 2. Comparison of results for Landsat-7, 14th June, 2002 image.

\begin{tabular}{|c|c|c|c|c|c|c|c|c|c|}
\hline Land cover/use & $\begin{array}{l}T s_{m_{-}} J \\
{ }^{\circ} \mathrm{C}\end{array}$ & $\sigma_{J}$ & $\begin{array}{l}T s_{m-} Q \\
{ }^{\circ} \mathrm{C}\end{array}$ & $\sigma_{Q}$ & $\begin{array}{c}T s_{m-} A \\
{ }^{\circ} \mathrm{C}\end{array}$ & $\sigma_{A}$ & & $\Delta_{J}$ & $\Delta_{Q}$ \\
\hline 2.1 Arable land & 23.19 & 2.25 & 21.73 & 2.02 & 23.69 & 0.81 & & 0.50 & 1.96 \\
\hline 2.2 Permanent crops & 22.31 & 1.56 & 20.91 & 1.42 & 23.57 & 0.83 & & 1.26 & 2.66 \\
\hline $\begin{array}{l}2.4 \text { Heterogeneous } \\
\text { agricultural areas }\end{array}$ & 22.62 & 1.89 & 21.20 & 1.71 & 23.59 & 0.73 & & 0.97 & 2.39 \\
\hline $\begin{array}{l}3.2 \mathrm{Scrub} \text { and/or } \\
\text { herbaceous vegetation } \\
\text { associations }\end{array}$ & 22.74 & 1.54 & 21.33 & 1.40 & 23.43 & 0.53 & & 0.69 & 2.10 \\
\hline \multirow[t]{4}{*}{$\begin{array}{l}3.3 \text { Open spaces with } \\
\text { little or no vegetation }\end{array}$} & 22.28 & 5.98 & 20.91 & 5.35 & 23.38 & 0.38 & & 1.10 & 2.47 \\
\hline & & & & & & & $\Delta_{m}$ & 0.90 & 2.32 \\
\hline & & & & & & & $\sigma$ & 0.31 & 0.28 \\
\hline & & & & & & & $R M S D$ & 0.94 & 2.33 \\
\hline
\end{tabular}

The Land Surface Temperature maps corresponding to the two processed satellite images are shown in Figure 4 and Figure 5 respectively.

\section{Comparison of LST results with the field mea- sured surface temperature}

A comparison was made between the results obtained by the application of the two previously described algorithms and the surface temperature measured in situ at the 11 meteorological ALSIA stations located in the Ionian band of the Basilicata region (Figure 6).

The agro-meteorological ALSIA stations are equipped with instruments for automatic, continuous measuring of different meteorological parameters, such as air temperature, air relative humidity, global solar radiation, soil temperature, wind speed and direction, precipitation and leaf wetness.

In particular, air temperature is measured with PT100 thermo-resistances with a precision of $\pm 0.1^{\circ} \mathrm{C}$, while soil temperature is measured with a Campbell Scientific Model
107 Temperature Probe, in the range from $-35^{\circ} \mathrm{C}$ to $+50^{\circ} \mathrm{C}$ and with an accuracy of $\pm 0.4^{\circ} \mathrm{C}$.

The comparison was made for different land uses, referring to the CORINE Land Cover map (Figure 7).

The values provided by the 11 ALSIA weather stations were interpolated on the entire Basilicata Ionian band, in order to make a comparison with the estimated LST maps. Of the different interpolation methods, the best performance was obtained by the Inverse Distance Weighting (IDW).

Table 1 and Table 2 show the comparison between the LST estimated by the application of the two Qin et al. (2001) and Jiménez-Muñoz and Sobrino (2003) algorithms and ALSIA field measurements of surface temperature, for each processed Landsat image and for different land uses.

Each table contains the mean value of LST for each land use or land cover, corresponding to the Jiménez-Muñoz \& Sobrino algorithm $\left(T s_{m-} J\right)$, the Qin et al. algorithm $\left(T s_{m-} Q\right)$, and ALSIA measurements $\left(T s_{m-} A\right)$, with the relative standard deviations $\left(\sigma_{J}, \sigma_{Q}, \sigma_{A}\right)$. The last two columns of each table contain the differences between estimated and measured values both for the Jiménez-Muñoz \& Sobrino al- 
gorithm $\left(\Delta_{J}\right)$ as well as the Qin et al. algorithm $\left(\Delta_{Q}\right)$. Total mean difference, $\Delta_{m}$, standard deviation, $\sigma$, and RMSD (Root Mean Square Deviation) are finally reported.

Note that due to the IDW interpolation of ground measurements, mean and standard deviation were not calculated just on a few values ( 5 classes, 11 stations), but on areal values, i.e. on the infinite points falling within the areas corresponding to the 5 classes of land use in the tables.

The results show that both methods lend themselves well to estimating LST, but the Jiménez-Muñoz and Sobrino (2003) model, in this case, provides values closer to the field measured data. In fact, for the 1999 Landsat-7 image, the LST evaluated by applying the Jiménez-Muñoz and Sobrino (2003) algorithm provides a mean difference from the field data, $\Delta_{m}$, of -0.40 (better than the +1.96 obtained from Qin et al.), with a standard deviation $\sigma=0.47$ ( 0.46 obtained from Qin et al.) and an $R M S D=0.58$ (lower than the 2.00 obtained from Qin et al.). For the 2002 Landsat-7 image $\Delta_{m}=+0.90$ ( +2.32 from Qin et al.), $\sigma=0.31$ ( 0.28 from Qin et al.) and $R M S D=0.94$ (2.33 from Qin et al.).

These results coincide with the results presented by other authors (Sobrino et al., 2004), even if obtained in a different contest (Ionian band of the Basilicata region).

Furthermore, it should be noted that the LST is estimated by the Jiménez-Muñoz and Sobrino (2003) algorithm with an error lower than the generally accepted level of $\pm 1.5^{\circ} \mathrm{C}$ with respect to field measurements. Therefore, it can be concluded that the LST distribution obtained is very close to the in situ measurements.

However, it should be considered that this is only a first application to the study area. In fact, in absence of ground radiometric measurements of land surface temperature, ALSIA station soil temperature measurements, $T_{s}$, were compared to the results obtained by applying the two algorithms. This is a strong approximation, but the aim of the work was not a numeric comparison, rather a comparative test of the two models, applying them in a context different from that for which they were designed, pending the radiometric measurement campaign planned for a near future, in the study area, in order to be able to further validate the results obtained.

\section{Conclusions}

Land Surface Temperature, controlled by the atmospheric state and surface emissivity, is an important factor controlling most of the physical, chemical, and biological processes of the Earth (Becker and $\mathrm{Li}, 1990)$. In spite of the great importance in modeling and applying LST, confusions exist in both the use of the term and its determination with satellite thermal data.

Landsat TM/ETM+ sensors have only one thermal infrared band (10.44 - $12.42 \mathrm{~mm}$ ), which makes the use of general split-window correction algorithm impossible, but the high spatial resolutions (120 m for TM and $60 \mathrm{~m}$ for ETM+) are much attractive in the local and regional thermal infrared study (Yang and Wang, 2002).
Several approaches have been developed for the retrieval of LST from TIR data in the last 20 years. All these techniques need to be validated with ground measurements, what is rarely done because of the difficulty of making ground measurements of LST comparable with satellite data (Coll et al., 2005).

In this study, two single-channel algorithms, based on Landsat IR thermal data, were applied to the Ionian band of the Basilicata region (South Italy) in order to retrieve LST from known LSE values obtained using the NDVI method. One of them, developed by Qin et al. (2001), uses the atmospheric water vapor content and the near-surface air temperature for retrieving the LST, whereas the other one, developed by Jiménez-Muñoz and Sobrino (2003), only uses the atmospheric water vapor content.

The test of these two algorithms was carried out from two Landsat-7 ETM+ images acquired on 09th August, 1999 and 14th June, 2002.

The main objective of the study was to obtain reasonable accuracy in the determination of LST from ETM+ thermal data using the available in situ and remote sensing parameters, when the Radiative Transfer Equation is not applicable due to the lack of radiosoundings.

A comparison was also made between the estimation of LST by applying the two algorithms and the surface temperature measurements collected at the meteorological ALSIA stations located in the study area.

The analysis carried out showed that both the models are able to represent the LST with a certain reliability, even though the Jiménez-Muñoz \& Sobrino algorithm seems to provide, in this case, a better estimate of LST from Landsat-7 ETM+ and to be more suitable to represent the in situ measured data.

A radiometric measurement campaign, planned for the near future in the study area, will validate the results obtained more accurately.

Acknowledgements. The authors would like to express their gratitude to ALSIA (Agenzia Lucana di Sviluppo e di Innovazione in Agricoltura) for providing field data.

\section{References}

APAT, 2005: The project IMAGE and CORINE Land Cover 2000 in Italy, Final report, April 2005.

Becker, F. and Li, Z. L., 1990: Temperature independent spectral indices in thermal infrared bands, Remote Sens Environ, 32, 1733, doi: 10.1016/0034-4257(90)90095-4.

Carlson, T. N. and Ripley, D. A., 1997: On the relation between NDVI, fractional vegetation cover, and leaf area index, Remote Sens Environ, 62, 241-252, doi: 10.1016/S00344257(97)00 104-1.

Chavez, P. S., 1996: Image-based atmospheric correction-revisited and improved, Photogramm Eng Remote Sens, 62, 1025-1036.

Coll, C., Caselles, V., and Galve, J. M., 2005: Ground measurements for the validation of land surface temperatures derived from AATSR and MODIS data, Remote Sens Environ, 97, 288300, doi: 10.1016/j.rse.2005.05.007. 
Cooper, D. I. and Asrar, G., 1989: Evaluating atmospheric correction models for retrieving surface temperature from AVHRR over a tallgrass prairie, Remote Sens Environ, 27, 93-102, doi: 10.1016/0034-4257(89)90040-0.

Cristóbal, J., Jiménez-Muñoz, J. C., Sobrino, J. A., Ninyerola, M., and Pons, X., 2009: Improvements in land surface temperature retrieval from the Landsat series thermal band using water vapor and air temperature, J Geophys Res, 114, D08 103, doi:10.1029/2008JD010616.

Dousset, B. and Gourmelon, F., 2003: Satellite multi-sensor data analysis of urban surface temperatures and land cover, ISPRSJ Photogramm Remote Sens, 58, 43-54, doi: 10.1016/S09242716(03)00 016-9.

Gillespie, A. R., Rokugawa, S., Hook, S., Matsunaga, T., and Kahle, A. B., 1998: A temperature and emissivity separation algorithm for Advanced Spaceborne Thermal Emission and Reflection Radiometer (ASTER) images, IEEE Trans Geosci Remote Sensing, 36, 1113-1126, doi: 10.1109/36.700995.

Iqbal, M., 1983: An introduction to solar radiation, Academic Press, New York.

Jiménez-Muñoz, J. C. and Sobrino, J. A., 2003: A generalized single channel method for retrieving land surface temperature from remote sensing data, J Geophys Res, 108, doi: 10.1029/2003JD003 480.

Jiménez-Muñoz, J. C., Cristóbal, J., Sobrino, J. A., Sòria, G., Ninyerola, M., and Pons, X., 2009: Revision of the SingleChannel Algorithm for Land Surface Temperature Retrieval From Landsat Thermal-Infrared Data, IEEE Trans Geosci Remote Sensing, 47, 339-349, doi: 10.1109/TGRS.2008.2007 125.

Mallick, J., Kant, Y., and Bharath, B. D., 2008: Estimation of land surface temperature over Delhi using Landsat-7 ETM+, J Ind Geophys Union, 12, 131-140.

Norman, J. M., Chen, J. L., and Goel, N. S., 1990: Thermal emissivity and infrared temperature dependence of plant canopy architecture and view angle, Proc. 10th Ann. Inter. Geoscience Remote Sensing Symp., IEEE, 445 Hoes Lane, Piscataway, NJ 08854, vol. III, pp. 1747-1750.

Qin, Z., Karnieli, A., and Berliner, P., 2001: A monowindow algorithm for retrieving land surface temperature from Landsat TM data and its application to the IsraelEgypt border region, Int J Remote Sens, 22, 3719-3746, doi: 10.1080/01431160010006971.

Running, S. W., Justice, C., and Salomonson, V., 1994: Terrestrial remote sensing science and algorithms planned for EOS/MODIS, Int J Remote Sens, 15, 2620-3587, doi: 10.1080/01431169408954346.

Sobrino, J. A., 1989: Desarrollo de un modelo teórico para implementar la medida de la temperatura realizada mediante teledetección. Aplicación a un campo de naranjos, $\mathrm{PhD}$ dissertation, University of Valencia, Valencia, $170 \mathrm{pp}$.

Sobrino, J. A. and Raissouni, N., 2000: Toward remote sensing methods for land cover dynamic monitoring. Application to Morocco, Int J Remote Sens, 21, 353-366, doi: 10.1080/014311600210876.

Sobrino, J. A., Caselles, V., and Becker, F., 1990: Significance of the remotely sensed thermal infrared measurements obtained over a citrus orchard, ISPRS-J Photogramm Remote Sens, 44, 343354, doi: 10.1016/0924-2716(90)90077-O.

Sobrino, J. A., Jiménez-Muñoz, J. C., and Leonardo, P., 2004: Land surface temperature retrieval from LANDSAT TM 5, Remote Sens Environ, 90, 434-440, doi: 10.1016/j.rse.2004.02.003.
Sobrino, J. A., Jiménez-Muñoz, J. C., Sòria, G., Romaguera, M., Guanter, L., Moreno, J., Plaza, A., and Martínez, P., 2008: Land Surface Emissivity Retrieval From Different VNIR and TIR Sensors, IEEE Trans Geosci Remote Sensing, 46, 316-327, doi: 10.1109/TGRS.2007.904 834.

Sun, Q., Tan, J., and Xu, Y., 2010: An ERDAS image processing method for retrieving LST and describing urban heat evolution: a case study in the Pearl River Delta Region in South China, Environ Earth Sci, 59, 1047-1055, doi: 10.1007/s12 665-009_ 0096-3.

Valor, E. and Caselles, V., 1996: Mapping land surface emissivity from NDVI: application to European, African and South American areas, Remote Sens Environ, 57, 167-184, doi: 10.1016/0034-4257(96)00 039-9.

Van de Griend, A. A. and Owe, M., 1993: On the relationship between thermal emissivity and the normalized difference vegetation index for natural surfaces, Int J Remote Sens, 14, 11191131, doi: 10.1080/01431169308904 400.

Wan, Z. and Snyder, W., 1996: MODIS land-surface temperature algorithm theoretical basis document, LST ATBD, version 3.2.

Weng, Q., Lu, D., and Schubring, J., 2004: Estimation of land surface temperature-vegetation abundance relationship for urban heat island studies, Remote Sens Environ, 89, 467-483, doi: 10.1016/j.rse.2003.11.005.

Wukelic, G. E., Gibbons, D. E., Martucci, L. M., and Foote, H. P., 1989: Radiometric calibration of Landsat Thematic Mapper Thermal Band, Remote Sens Environ, 28, 339-347, doi: 10.1016/0034-4257(89)90 125-9.

Yang, J. S. and Wang, Y. Q., 2002: Estimation of land surface temperature using landsat-7 ETM+ thermal infrared and weather station data, Proceeding from Huangshan International Thermal Infrared Remote Sensing Workshop, Huangshan, Anhui, PR China, July 14-17, 2002, http://www.ltrs.uri.edu/research/ LST_page/paper4.doc.

Zhang, J., Wang, Y., and Lib, Y., 2006: A $C++$ program for retrieving land surface temperature from the data of Landsat TM/ETM+ band6, Comput Geosci, 32, 1796-1805, doi: 10.1016/j.cageo.2006.05.001.

Zhang, J., Wang, Y., and Wang, Z., 2007: Change analysis of land surface temperature based on robust statistics in the estuarine area of Pearl River (China) from 1990 to 2000 by Landsat TM/ETM+ data, Int J Remote Sens, 28, 2383-2390, doi: 10.1080/01431160701236811. 